\title{
Associations of atmospheric teleconnections with wintertime extratropical cyclones over East Asia and Northwest Pacific
}

\author{
Meng Gao ${ }^{1,2,4} \cdot$ : Yidi Sun ${ }^{2,3} \cdot$ Qian Zheng ${ }^{2,3}$
}

Received: 26 December 2020 / Accepted: 29 April 2021 / Published online: 10 May 2021

(c) The Author(s), under exclusive licence to Springer-Verlag GmbH Germany, part of Springer Nature 2021

\begin{abstract}
Extratropical cyclones (ETCs) over East Asia and Northwest Pacific are identified and tracked by applying an objective algorithm to the 850-hPa relative vorticity fields from the ERA-Interim reanalysis. A total of 2866 ETCs originating at the western side of the date line have been identified in the extended November-March winters from 1979 to 2018. The ETC tracks are counted and visualized using a hexagonal tessellation rather than the regular longitude-latitude grids. Two generalized linear models (GLMs), Poisson regression model and Gamma regression model, are firstly applied to investigate the associations of wintertime ETCs with three atmospheric teleconnection patterns. The West Pacific (WP) pattern and the Pacific/North American (PNA) pattern are more responsible for the meridional variability of ETC activities in the North Pacific, while the influence of the Polar/Eurasia pattern on ETC activities is negligible. Results of composite analysis are qualitatively consistent with that of regression analysis. Composite maps of differences of jet stream, thermal gradient and mid-tropospheric baroclinicity in the positive and negative phases of teleconnection patterns also support the close associations of ETC activities with WP and PNA teleconnection patterns.
\end{abstract}

Keywords Hexagon grid · Teleconnection pattern · Inhomogenous Poisson process · Generalized linear model

\section{Introduction}

Extratropical cyclone (ETC), also called wave cyclone or midlatitude cyclone, is a type of storm system in middle or high latitudes transporting huge amounts of moisture and energy poleward to reduce the meridional temperature gradient (Zhang and Rossow 1997; Chang et al. 2002). The passage of ETC is usually associated with strong winds, excessive precipitation, and temperature changes (Raible 2007; Ulbrich et al. 2009; Hawcroft et al. 2012; Catto

\section{Meng Gao}

mgao@yic.ac.cn

1 School of Mathematics and Information Sciences, Yantai University, Yantai 264005, China

2 Key Laboratory of Coastal Environmental Processes and Ecological Remediation, Yantai Institute of Coastal Zone Research, Chinese Academy of Sciences, Yantai 264003, China

3 University of Chinese Academy of Sciences, Beijing 100049, China

4 Center for Ocean Mega-Science, Chinese Academy of Sciences, Qingdao 266071, China
2016). Because of their large impact on global circulation and hydrological cycle, ETCs have been the focus of weather forecast and weather understanding for a long time (Ulbrich et al. 2009; Lee et al. 2012).

A preliminary study on ETC climatology includes but not limited to the basic properties such as genesis, lysis, frequency and intensity etc. Both historical and projected changes of ETCs are important research themes (Ulbrich et al. 2009; Pinto et al. 2013; Tamarin-Brodsky and Kaspi 2017; Lee et al. 2020). Many recent studies showed the evidence of trend and variability in cyclone activity revealed by the reanalysis datasets and the ensemble of Global Climate Models (GCMs) (Ulbrich et al. 2009 and references therein; Tamarin-Brodsky and Kaspi 2017). Naturally, climatologists were also prone to explain these variabilities from the view of climate teleconnections like the North Atlantic Oscillation (NAO), the Pacific Decadal Oscillation (PDO) and El Niño-Southern Oscillation (ENSO), because these teleconnection patterns might influence the development, movement and lysis of ETCs (Eichler and Higgins 2006; Wang et al. 2006; Plante et al. 2015; Reboita et al. 2015; Lee et al. 2012; Varino et al. 2019). Conversely, ETCs could be also seen as perturbations of the large-scale atmospheric flow 
on synoptic or subsynoptic scales that exert influence on these large-scale flow patterns (Zhu et al. 2007; Pinto et al. 2009). Gulev et al. (2001) pointed out that the relationship between cyclones and climate patterns was not fixed and unchangeable. Lee et al. (2012) showed that the cyclone activity over North Pacific was well correlated with the PDO before 1980s, but the correlation became weaker afterward.

Statistics is an efficient way to describe the climatic properties of cyclones and revealing the underlying mechanisms of variability of cyclone activity (Elsner and Villarini 2011). Generally, cyclone activities could be indicated based on either cyclone tracks or eddy variance statistics (Gulev et al. 2001; Lee et al. 2012; Chang and Yau 2016; Xie et al. 2019). Relatively speaking, cyclone tracks can give more information about the lifecycle of ETC from initiation, mature, decay and lysis (Varino et al. 2019). The relations between teleconnection patterns and cyclone activities could be analyzed via correlation analysis or composite analysis (Gulev et al. 2001; Lee et al. 2012; Plante et al. 2015; Reboita et al. 2015; Xie et al. 2019). Moreover, the links between cyclone activity and teleconnection patterns could also be analyzed using the regression model (Mailier et al. 2006; Vitolo et al. 2009; Hunter et al. 2016). The occurrence of ETC in time could be modeled by a stochastic point process (Mailier et al. 2006), and the real process was more clustered than random. This serial clustering is of particular concern in evaluating the cumulative risk of wind storms (Pinto et al. 2014; Hunter et al. 2016). Franzke et al. (2020) hypothesized that the serial clustering might be an intrinsic property of nonlinear dynamics and an imprint of scaling. Then, an inhomogeneous Poisson process or a fractional Poisson process could be more qualified for describing serial clustering (Mailier et al. 2006; Franzke 2013; Blender et al. 2015, 2017).

Serial clustering of ETCs has been analyzed from a statistical perspective, although the research about the physical drivers of clustering is still ongoing (Katz 2002; Mailier et al. 2006; Vitolo et al. 2009; Hunter et al. 2016). Mailier et al. (2006) developed a Poisson regression model for the ETC count in North hemisphere to assess the association with large-scale flow patterns. Vitolo et al. (2009) fitted the intense cyclones in Europe using the similar Poisson regression model and found that intense ETCs were more clustered. Hunter et al. (2016) investigated the correlations between frequency and intensity of wintertime ETCs over North Atlantic by regressing ETC count and intensity on teleconnection indices with Poisson and linear models, respectively. The ETC intensity was usually measured based on either mean sea level pressure (SLP) or relative vorticity (Ulbrich et al. 2009). Therefore, Gamma regression model is better than linear regression for modeling positive ETC intensity (Seierstad et al. 2007). Both Poisson regression and Gamma regression belong to the family of generalized linear model (GLM), where the response variable follows non-normal distributions and is indirectly related to the linear combination of predictors (Dobson 1990).

In the Northern Hemisphere, ETCs are mostly active over the North Atlantic (NA) and the North Pacific (NP), as well as the Asian continent and the Mediterranean region (Hoskins and Hodges 2002; Ulbrich et al. 2009). Over East Asia and Northwest Pacific, ETCs are key factors of regional climate system, particular in the autumn and winter (Yoshida and Asuma 2004; Iwao et al. 2012). The climatic properties of East Asian ETCs have been well documented in previous studies (Chung et al.1976; Whittaker and Horn 1984; Chen et al. 1991; Adachi and Kimura 2007; Zhang et al. 2012; Lee et al. 2020), and the major cyclogenesis regions range from Mongolia and East China to the Pacific coast (Wang et al. 2009; Zhang et al. 2012; Xie et al. 2019). The leeward terrain contributed to the cyclogenesis of continental ETCs over East Asia, while Kuroshio Current contributed to the cyclogenesis of oceanic ETCs (Zhang et al. 2012; Chen et al. 2014; Lee et al. 2020). ETCs originating in East Asia usually enter the Northwest Pacific and intensify as explosive ETCs, because Northwest Pacific is on the left of the outlet of the upper level jet (Zhang et al. 2012).

Previous studies showed that both oceanic and atmospheric teleconnections more or less accounted for the variability of ETC activity. Chang and Fu (2002) showed that the North Pacific cyclone activity was significantly correlated with the PDO index. Specifically, a northeastward shift of the North Pacific storm tracks in the negative phase of PDO could be explained by the increased sea surface temperature (SST) increased on the northern side of North Pacific basin (Barton and Ellis 2009). The associations of the North Pacific storm track with ENSO were also mentioned in Orlanski (2005) as well as Eichler and Higgins (2006). Gulev et al. (2001) found that the eastern Pacific cyclone activity was once largely linked with the Pacific/North American (PNA) teleconnection pattern. Pinto et al. (2011) showed the meridional shift of Pacific cyclone activity in different phases of PNA based on a multi-century coupled global circulation model (CGCM) simulation. Mailier et al. (2006) pointed out that a single teleconnection pattern was not sufficient for explaining the variability of cyclone frequency. Seierstad et al. (2007) identified PNA as the dominant factor for controlling North Pacific storminess. To our best knowledge, the associations of multiple atmospheric teleconnections with wintertime extratropical cyclones over East Asia and Northwest Pacific have not been investigated based on GLMs.

It has been verified that there is obvious spatial variability in the relationship between large-scale teleconnections and ETC activity (Plante et al. 2015; Hunter et al. 2016). When cyclone tracks were used to define storm activity, the time series of cyclone count was constructed in either a spatially implicit or explicit way. For the spatially implicit way, the 
time series is actually the basin-wide count of cyclones (Katz 2002; Kozar et al. 2012). Thus, the zonal and meridional variations in the location and intensity of ETCs could not be properly reflected. Alternatively, the study area could be discretized using the regular latitude and longitude grids or hexagonal grids. At each grid point only cyclones passing within a few hundred kilometers radius circle (Pinto et al. 2014; Economou et al. 2015) or transiting across the local meridian within $\pm 10^{\circ}$ of latitude from the grid point (Mailier et al. 2006; Vitolo et al. 2009; Hunter et al. 2016) were considered as the local cyclone counts. Elsner et al. (2012a) proposed to discretize the study area using equal area hexagons, and the spatial climatology of cyclones could be presented (Elsner et al. 2012b; Fraza and Elsner 2014; Trepanier et al. 2015). Then the cyclone data as a temporal sequence of points over space could be easily linked with climate information given in the form of field data based on all kinds of statistical models (Elsner et al. 2012a).

The major objective of this study is to reveal the statistical associations of three atmospheric teleconnections with wintertime extratropical cyclones over East Asia and Northwest Pacific. An automated tracking algorithm is firstly used to identify and track ETCs in the extended winters during the period 1979-2018. Two GLMs, Poisson regression model for ETC counts and Gamma regression model for ETC intensities, are created to link ETC activities and atmospheric teleconnections. Unlike previous studies, the ETC statistics, i.e. ETC counts and ETC intensities, are computed based on the framework of hexagonal tessellation rather than the regular longitude-latitude grids. In addition, the influences of these three atmospheric teleconnections on ETC activities are also assessed via composite analysis. The following sections are organized as follows. Data and methods are described in Sect. 2. The results are presented and discussed in Sect. 3. Finally, the paper ends with a brief conclusion in Sect. 5.

\section{Data and methods}

\subsection{Data}

The European Centre for Medium range Weather Forecasts (ECMWF) reanalysis data (ERA-Interim for 1979-2018), with a $0.75^{\circ} \times 0.75^{\circ}$ horizontal resolution and 6-h time interval are used for automated ETC identification and tracking (Dee et al. 2011). The choice of the ECMWF reanalysis is due to its finer spatial resolution. The reliability of ERA-Interim reanalysis for ETC tracking was also verified in Chang and Yau (2016). The extended winter seasons lasting November-March (NDJFM) is adopted instead the conventional December-February (DJF) winter season in order to avoid missing the cyclones that occur in the autumn and early spring (Mailer et al. 2006; Hunter et al. 2016). October is excluded either, because tropical cyclones are still active in October over Northwest Pacific (Yonekura and Hall 2011).

To evaluate the influence of large-scale atmospheric flow on ETC activities, three atmospheric teleconnection patterns, which are particularly relevant for the East Asia and Northwest Pacific region and active in winter season, are chosen for statistical analysis. The three teleconnection patterns are specifically the West Pacific (WP) pattern, the Pacific/North American (PNA) pattern, and the Polar/ Eurasia (PEA) pattern. The standardized 3-month running mean value of the three indices are provided by NOAA Center for Weather and Climate Prediction. These indices are mutually uncorrelated by construction, which makes them particularly suitable for use as explanatory variables in regression analysis (Mailer et al. 2006).

\subsection{ETC identification and tracking}

The relative vorticity fields at $850-\mathrm{hPa}$ pressure level within the region $20^{\circ} \mathrm{N}-60^{\circ} \mathrm{N}, 60^{\circ} \mathrm{E}-120^{\circ} \mathrm{W}$ are used to identify and track wintertime ETCs based on the Lagrangian tracking algorithm (Hoskins and Hodges 2002). The relative vorticity (RV) is advantageous, because it allows for the early detection of weak and less organized ETCs (Hoskins and Hodges 2002; Lee et al. 2020). Flaounas et al. (2014) provided an efficient realization of this algorithm including two independent steps. The first step is devoted to the identification of the cyclone centers, which are combined into a cyclone track in the second step. This identification and tracking algorithm perform well in comparison with other techniques using 1000-hPa geopotential height or Minimum sea-level pressure (Flaounas et al. 2014). Firstly, only ETCs originating at the western side of the date line are kept for further statistical analysis in line with the study area of the paper, East Asia and Northwest Pacific. ETCs that affect the west coast of Canada and USA deserve another independent research in future work. The spurious paths of cyclones moving upstream/westward over five longitude degrees or having a lifetime less than $24 \mathrm{~h}$ are eliminated for the purpose of getting rid of local warm season thermal lows (Wang et al. 2009; Zhang et al. 2012) and some tropical cyclones moving westward (Zhu et al. 2000).

In this study, $\mathrm{RV}$ at $850-\mathrm{hPa}$ pressure level is used as the metric of ETC intensity. RV has also been used as the cyclone intensity measure in some previous studies on extratropical cyclone risk, because it is less influenced by the background state on smaller spatial scales (Mailier et al. 2006; Vitolo et al. 2009; Hunter et al. 2016). The temporal resolution of the extracted ETCs was 6-h 
identical to that of the ERA-Interim reanalysis data (Dee et al. 2011).

\subsection{Spatial grid}

The spatial framework proposed by Elsner et al. (2012a) was adopted for statistical analysis and modeling of ETCs. The framework consists of a tessellation of the East Asia and Northwest Pacific using equal-area hexagons. First, the geographic coordinates of the ETC centers are projected onto a Lambert conformal conic projection (true at $30^{\circ}$ and $60^{\circ} \mathrm{N}$ and centered at $160^{\circ} \mathrm{E}$ ) planar coordinate system. Next, a rectangular domain that encompasses the ETC tracks is gridded into equal-area hexagons. The size of the hexagons should be carefully selected, so that the grids are large enough to have a sufficient number of ETC samples, while being small enough that local variations are still meaningful (Elsner et al. 2012a; Trepanier et al. 2015). With the hexagonal grids, the spatial patterns of ETC tracks could be presented and visualized.

\subsection{Statistical analysis}

By defining a cyclone crossing any hexagon as an "event" and $n$ as the number of events in any calendar month, then $n$ could be modeled with a discrete Poisson distribution:

$P(n=x)=\frac{\lambda^{x} e^{-\lambda}}{x !}, x=0,1,2, \cdots$

If the rate parameter $\lambda$ is constant, the above point process is the simplest homogeneous Poisson process. Otherwise, a time-varying rate $\lambda_{t}$ corresponds to an inhomogeneous Poisson process, and the subscript $t$ is the month index. Then, the monthly ETC counts $n$ could be modeled using the Poisson regression with the log-link function:

$n \mid \lambda \sim \operatorname{Poisson}(\lambda)$

$\log (\lambda)=\alpha_{0}+\sum_{t=1}^{4} \alpha_{t} x_{t}+\sum_{k=1}^{3} \beta_{k} z_{k}$

Equation (2) means that the monthly ETC count $n$, conditional on a linear predictor $\lambda$, is Poisson distributed. Following Mailier et al., (2006), the seasonality is also considered in Poisson regression by including four binary indictor variables $x_{t}$ from December to March, while the fifth indictor for December is redundant and ignored. $z_{k}$ is the monthly index of the teleconnection patterns (WP, PNA, and PEA). The coefficients $\alpha_{t}$ and $\beta_{k}$ are estimated using the Maximum likelihood estimation method, and the regression coefficients deviating from zero at $5 \%$ statistically significance level is indicated based on the $t$-test.

The continuous Gamma distribution is flexible for modeling positively distributed values of different shapes. Like Seierstad et al. (2007), the ETC intensity in any hexagon is modeled using the Gamma regression model. The monthly ETC intensity $y$ in any hexagonal grid can be related to the teleconnection indices using the following GLM:

$y \mid \mu, \nu \sim \operatorname{Gamma}(\mu, \nu)$

$\log (\mu)=\alpha_{0}+\sum_{t=1}^{4} \alpha_{t} x_{t}+\sum_{k=1}^{3} \beta_{k} z_{k}$

Equation (4) means that the monthly ETC intensity, conditional on $\mu$ and $v$, is Gamma distributed. The shape parameter $v$ is usually assumed to be constant for simplicity. The interpretations of all coefficients and parameters on the right side of Eq. (5) are identical to those in Eq. (3). The coefficients $\alpha_{t}$ and $\beta_{k}$ are also estimated using the Maximum likelihood estimation method, and the statistical significance is determined by using likelihood test.

The influences of atmospheric teleconnection patterns on ETC activities are also examined by composite analysis. Specifically, twenty of the most/least active WP months are selected as positive/negative phases (denoted as WP+ and WP-), respectively. Then, the differences of ETC track densities or intensities are presented in the opposite phases of these teleconnection patterns. Similar composite analyses are also done for PNA and PEA patterns. Additionally, the large-scale environmental factors causing the differences of ETC activities are also investigated using composite analysis. Previous studies showed that an upper-level jet stream and a low-level baroclinicity accounted for the development of ETCs (Plante et al. 2015; Varino et al. 2019; Lee et al. 2020), and the meridional temperature gradient was closely related to the baroclinic Eddy activity (Hoskins and Hodges 1990). Therefore, the composite maps for differences of zonal wind at 300-hPa pressure level (U300), mean temperature at 850-hPa pressure level, and the Eady growth rate in the opposite phases are also created to further reveal the influences of atmospheric teleconnections on ETC activity. The Eady growth rate $(\sigma)$ is defined as:

$\sigma=0.31 f|\partial U / \partial Z| N^{-1}$

where $U$ is the zonal wind $(\mathrm{m} / \mathrm{s}), Z$ is the geopotential height $(m), f$ is the Coriolis parameter, and $N$ is the Brunt-Väisälä frequency representing atmospheric static stability. The computation of $\sigma$ is based on the zonal wind and the potential temperature at 500- and 850-hPa pressure levels. 


\section{Results}

We have identified 2866 ETCs totally in the extended winter seasons (NDJFM) from 1979 to 2018 over East Asia and Northwest Pacific. The whole study area was gridded using the hexagonal tessellation network, and different hexagon sizes have also been tested to balance the hexagon numbers and per hexagon ETC counts. The final hexagonal tessellation network consists of 660 hexagons, and the area of each hexagon is $149 \times 10^{3} \mathrm{~km}^{2}$. For the purpose of comparing different ETC counting methods mentioned in Introduction, the spatial patterns of ETC numbers estimated based on the regular longitude-latitude grids are also provided as supplementary materials.

Figure 1 shows the estimated coefficients in the Poisson regression model for monthly ETC counts using the maximum likelihood estimation method. Statistical significance

(a) WP

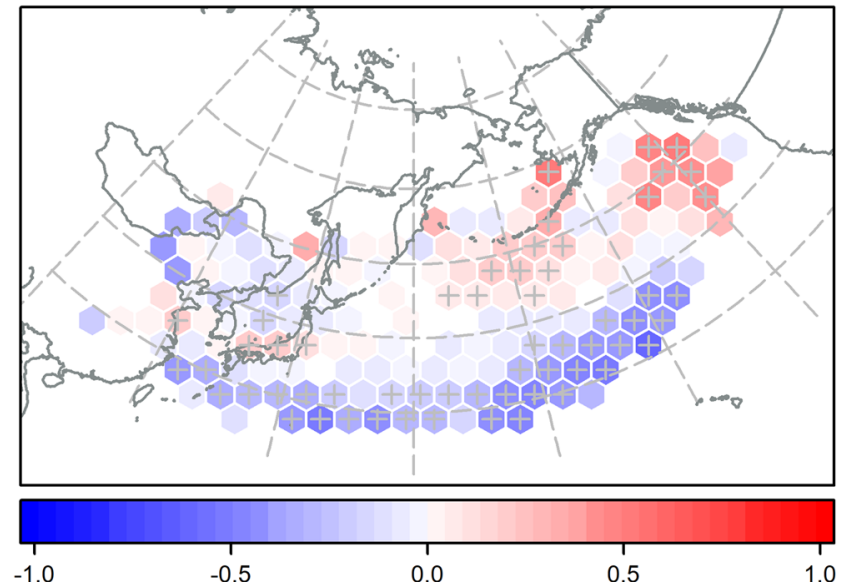

(c) PEA

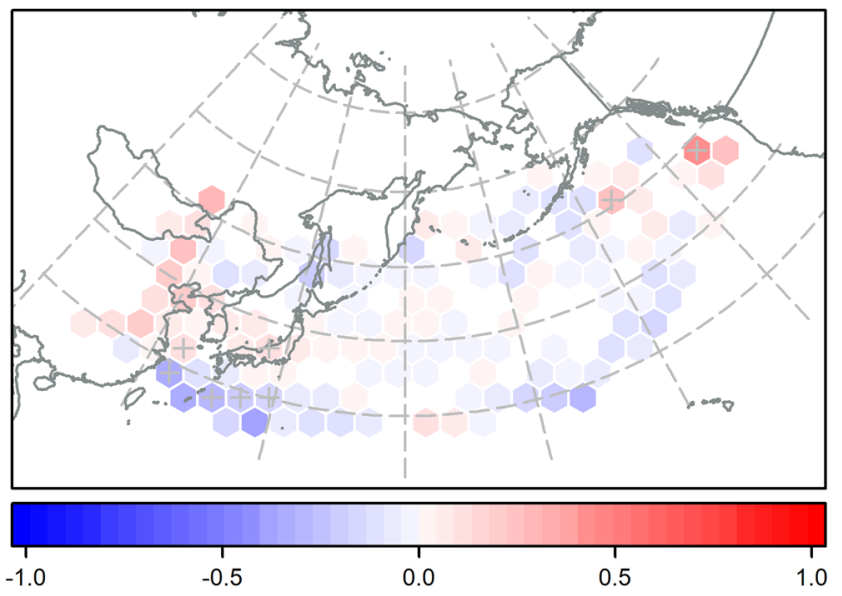

Fig. 1 Slope estimates from a Poisson regression of monthly ETC count (unit: ETC per month per hexagon), on a the West Pacific pattern, b the Pacific/North American pattern, and $\mathbf{c}$ the Polar/Eurasia is determined with a $t$-test at the 5\% significance level. The relationship between WP and ETC counts is clear over East Asia and Northwest Pacific, and the estimated coefficients are statistically significant in many hexagons. The positive WP phase is associated with the increasing in ETCs over North Pacific and central Japan, while the negative WP phase is associated with the decreasing of ETCs at the south edge of the ETC tracks, Northeast China and the Japan Sea (Fig. 1a). The PNA coefficient is statistically significant for ETC counts over North Pacific. From Fig. 1b, we find that the positive phase of the PNA is associated with an increase of ETC counts at the southern side of ETC tracks showing zonal distribution from southwest of Japan to the west coast of North America. Hexagons with negative PNA coefficients are mainly distributed around Aleutian Islands indicting a decrease in ETC counts in the negative phase of PNA (Fig. 1b). Statistically significant association between PEA and ETC counts has only been detected in a few hexagons

(b) PNA

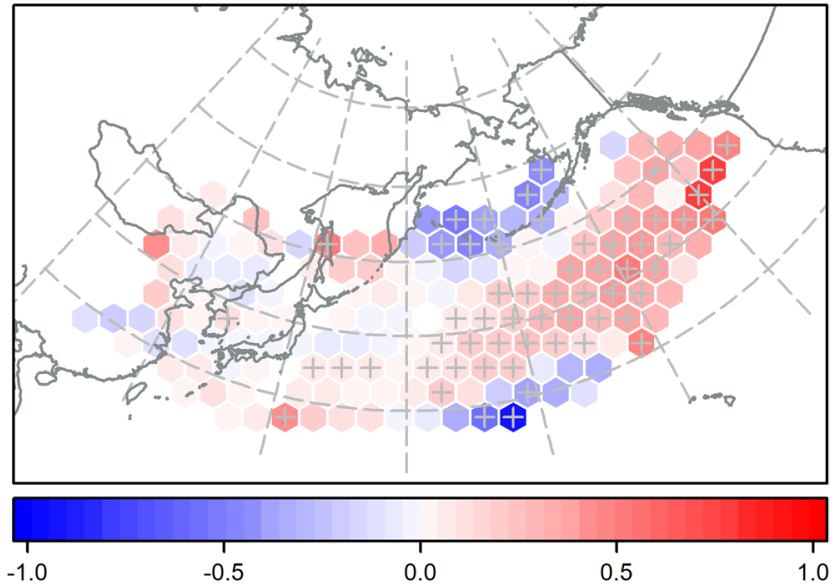


(Fig. 1c). The differences of ETC counts between the positive and the negative phases of WP, PNA, and PEA patterns are plotted in Fig. 2. Positive/negative value indicates more ETCs in the positive/negative phase of teleconnection patterns. Statistical significance is determined with a nonparametric Wilcoxon test at the 5\% significance level. Figure 2a clearly illustrated the WP-related meridional variability of ETC tracks over North Pacific, where ETC tracks are prone to shift northward in the positive phase of WP but shift southward in the negative phase. This result is basically in line with that revealed by the Poisson regression presented in Fig. 1a. The influence of PNA on ETC activity over North Pacific is almost opposite to that of WP, and the meridional variability of cyclone tracks is also very significant (Fig. 2b). The composite analysis also reveals that there is significant difference of ETC counts in positive and negative phases of PEA over East China Sea, Korean Peninsula and south Japan Sea indicting the influence of PEA on ETC activity in this region (Fig. 2c). In other regions, the influence of PEA is not statistically significant.

The influence of the three teleconnection patterns on the cyclone intensity revealed by Gamma regression is shown in Fig. 3. The positive phase of WP is associated with increased storminess over North Pacific ranging from the Kamchatka Peninsula to the west coast of North America (Fig. 3a), which is consistent with the association of WP pattern with ETC counts shown in Fig. 1a. However, the association of WP with ETC intensity in other regions is not significant. This result means that the cyclone frequency and cyclone intensity are not always positively correlated. The spatial patterns of PNA coefficients in Gamma regression and Poisson regression are similar (Figs. 1b, 3b). Analogously, no significant influence of PEA on ETC intensity has been detected over East Asia and Northwest Pacific (Figs. 1c, $3 c)$. Figure 4 presents the differences of ETC intensity between the positive and negative phases of WP, PNA, (a) WP+ minus WP-
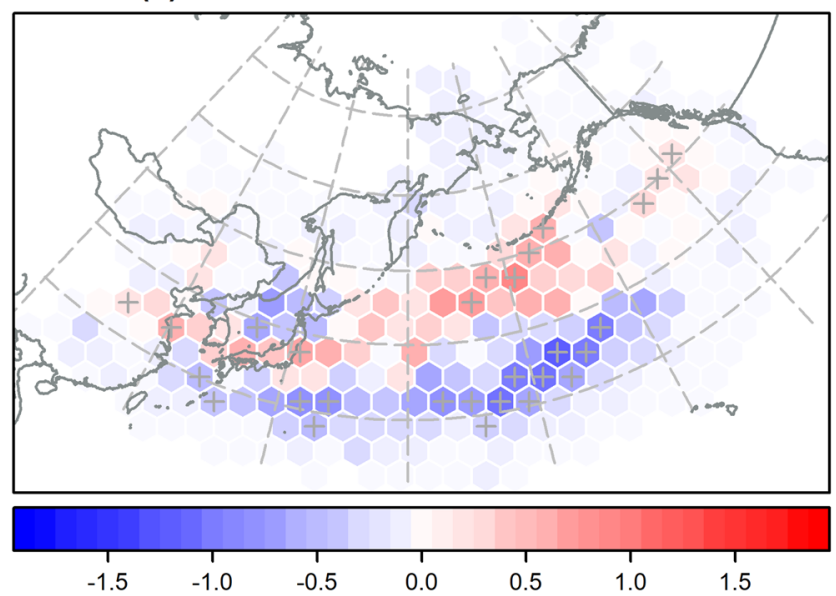

\section{(b) PNA+ minus PNA-}

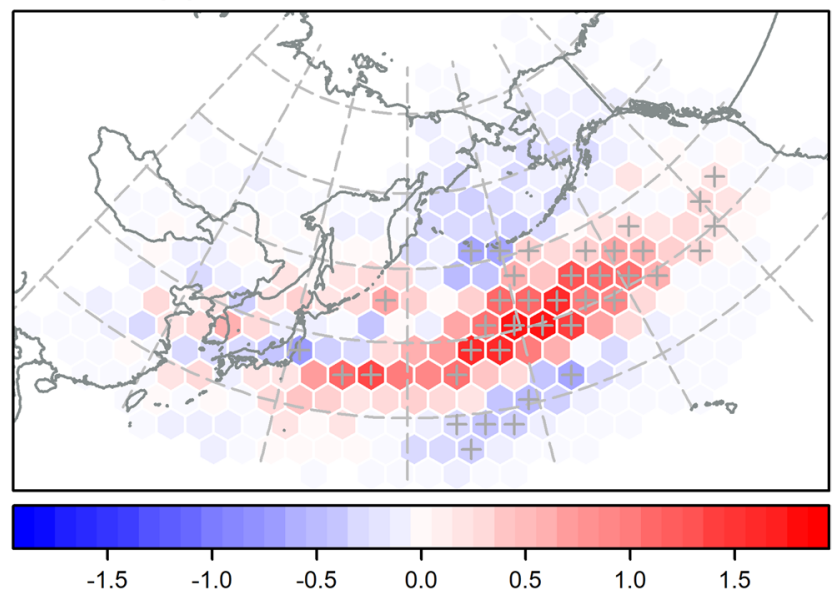

(c) PEA+ minus PEA-

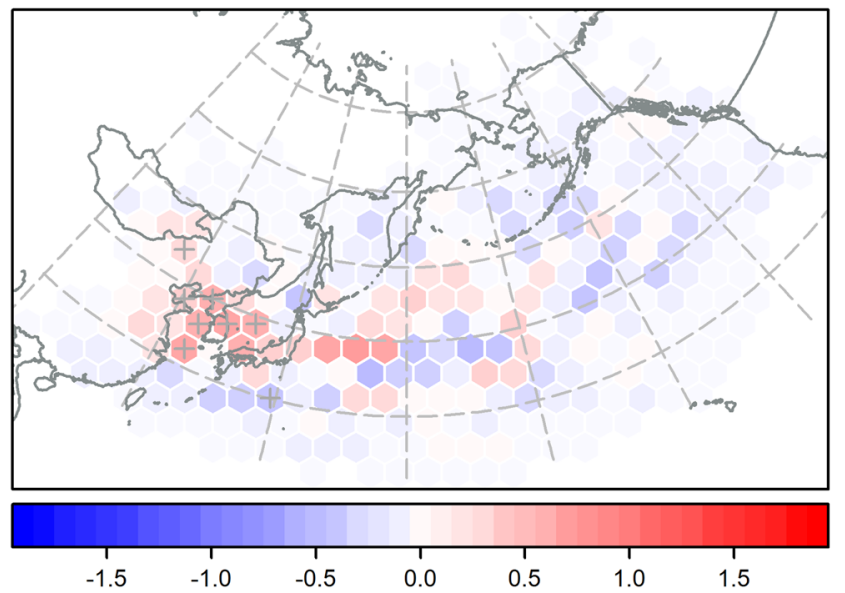

Fig. 2 Difference of the average of ETC count (unit: ETC per month per hexagon) in the 20 months with highest/lowest $( \pm)$ teleconnection indices. The symbol "+" in each hexagon indicates that the difference is significantly different in positive/negative phases at the $5 \%$ significance level, according to a nonparametric Wilcoxon test 
(a) WP

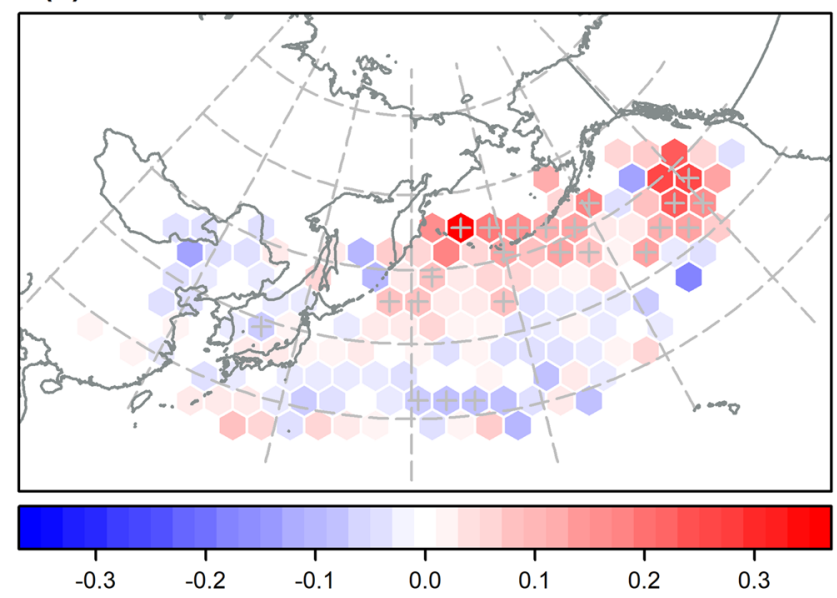

(b) PNA

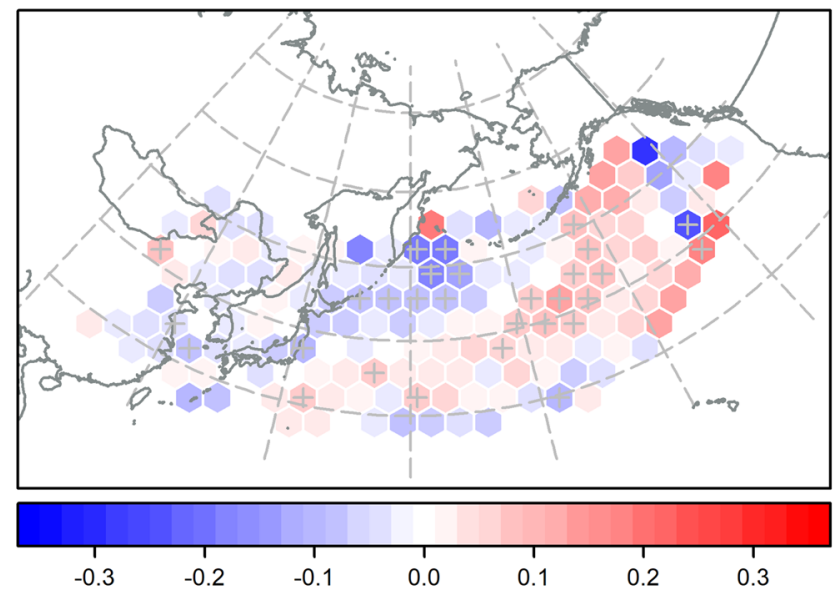

(c) PEA

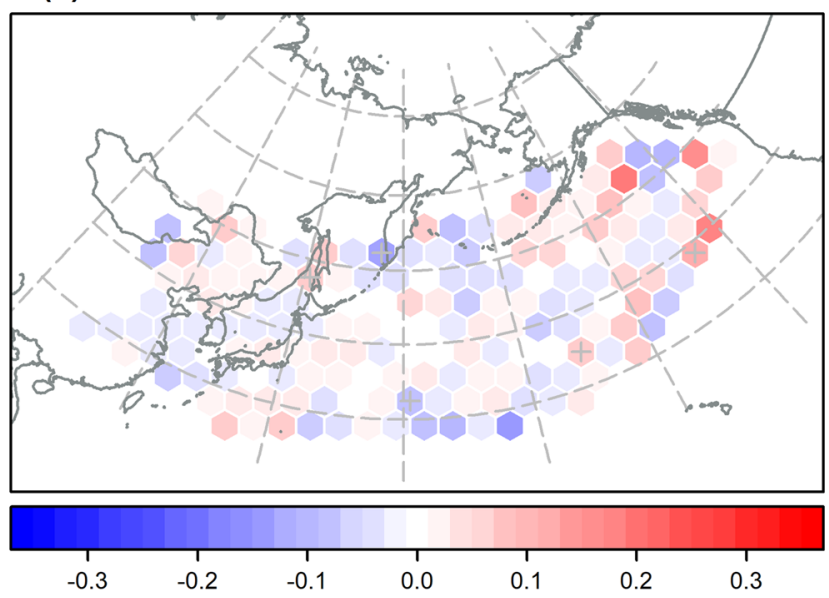

Fig. 3 Slope estimates from a Gamma regression of monthly ETC intensity (unit: $10^{5} \times \mathrm{s}^{-1}$ ), on a the West Pacific pattern, b the Pacific/ North American pattern, and $\mathbf{c}$ the Polar/Eurasia pattern. The symbol
"+" indicates that the estimated slope is significantly different from zero at the $5 \%$ significance level, according to a likelihood ratio-test

\section{Discussions} intense ETCs in the positive/negative phase of teleconnection patterns, and hexagons with too few ETC samples are neglected. Statistical significance is also determined with a nonparametric Wilcoxon test. Figure 4a shows that the positive phase of WP leads to increased cyclone intensity to the north of $40^{\circ} \mathrm{N}$, and significant associations are only located in a few hexagons. The north-south shift of ETC tracks in the positive and negative phases of PNA has also identified in Fig. 4b. The influence of PEA on ETC intensity is not obvious either according to the composite analysis (Fig. 4c), and significant coefficients are only located in four hexagons.
Large-scale atmospheric teleconnection is a reflection of internal atmospheric dynamics and also strongly influences regional weather system such temperature, precipitation, storm tracks, and jet stream location/ intensity (Ulbrich et al. 2009; Franzke et al. 2020). Barnston and Livezey (1987) identified ten teleconnection patterns that described the state of the large-scale flow for the Northern Hemisphere. These teleconnection indices are mutually uncorrelated by definition, making them useful as a basis for explanatory variables in regression models (Mailier et al. 2006). The relationships between cyclones and large-scale atmospheric teleconnection patterns are intensive and interactive (Ulbrich et al. 2009). In this study, three teleconnections (WP, PEA, and PNA), which are important modes of variability in the winter months over East Asia and Northwest Pacific, are 
(a) WP+ minus WP-

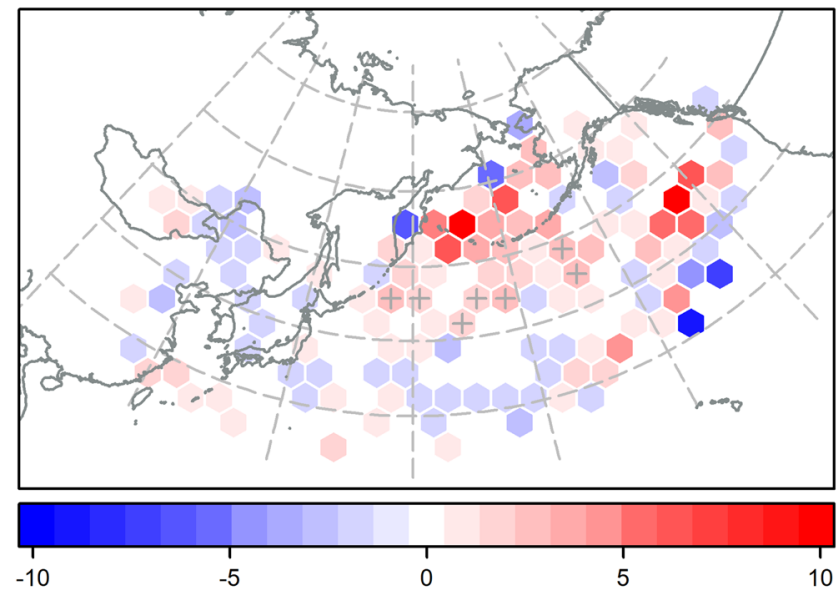

(b) PNA+ minus PNA-

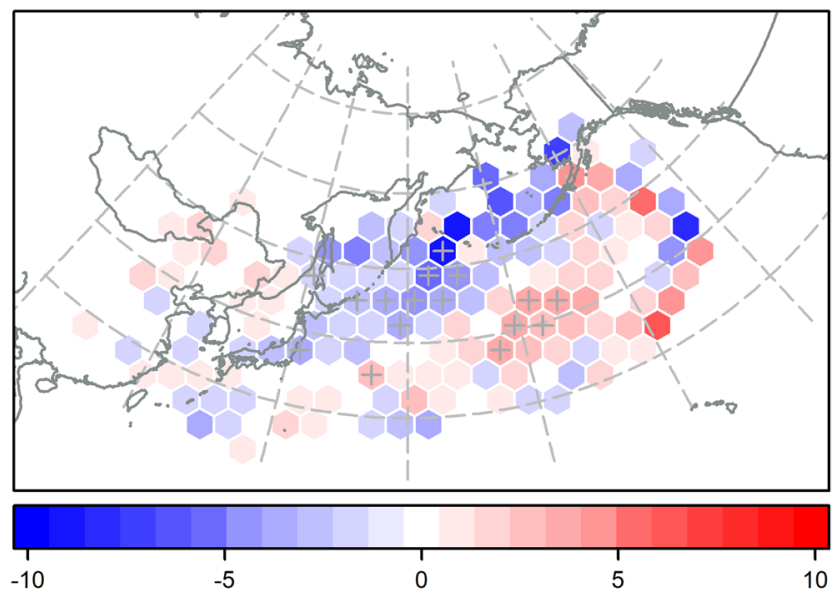

(c) PEA+ minus PEA-

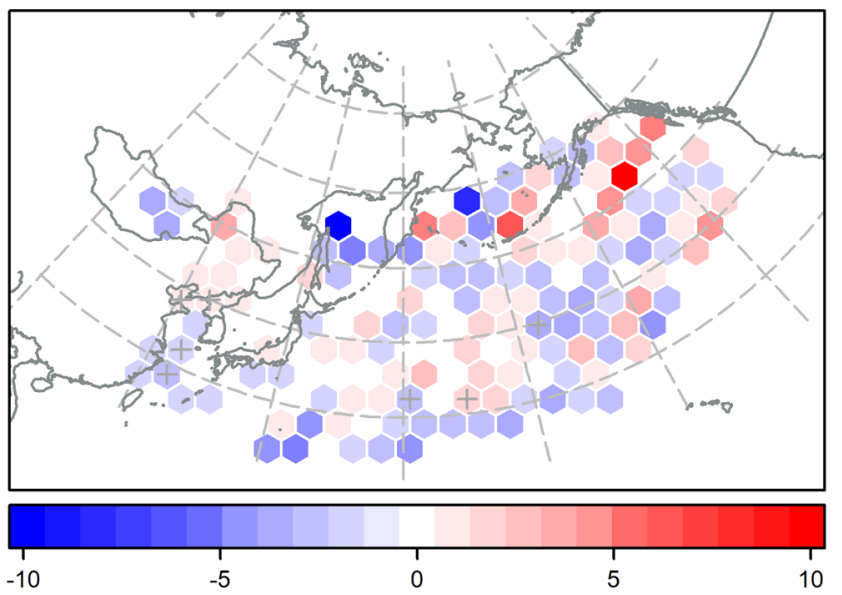

Fig. 4 Difference of the average of ETC intensity (unit: $10^{5} \times \mathrm{s}^{-1}$ ) in the 20 months with highest/ lowest $( \pm)$ teleconnection indices.

considered (Fig. 5). Both cyclone counts and intensities have been regressed on the three time-varying teleconnection indices with two GLMs, Poisson regression and Gamma regression. In general, the influences of these three teleconnection patterns on ETC activity revealed by the regression analysis and composite analysis are qualitatively consistent (Figs. 1, 2, 3, 4).

The WP teleconnection pattern can be identified from the geopotential height anomaly field existing throughout the year (Barnston and Livezey 1987), which is characterized by a dipole in the geopotential height field in the western sector of North Pacific with negatively correlated centers in the mid-latitude and subtropics (Fig. 5a, b). In this study, both the regression analysis and composite analysis confirm that the meridional variability of ETC frequency and intensity are related to the WP teleconnection pattern. This finding is in a qualitative agreement with that presented by
The symbol "+" in each hexagon indicates that the difference is significantly different in positive/negative phases at the 5\% significance level, according to a nonparametric Wilcoxon test

Seierstad et al. (2007). Unlike tropical cyclones, ETCs get their energy from the jet stream and from temperature differences between cold, dry air masses from higher latitudes and warm, moist air masses from lower latitudes. Previous studies also showed that strong positive or negative phases of WP pattern reflected pronounced zonal and meridional variations in the location and intensity of the entrance region of the North Pacific jet (Choi and Moon 2012). The meridional variability of North Pacific jet for the two WP phases can be revealed by the difference of zonal wind at $300-\mathrm{hPa}$ pressure level. We find that in the positive WP phase, the jet is located more to the north, but in the negative phase, the jet is located more to the south (Fig. 6a). It indicates that both North Pacific jet and ETC activity are closely related to WP. In addition, we plot the difference of mean temperature at 850 -hPa pressure level; because the mid-tropospheric baroclinicity is also related to the meridional temperature 
Fig. 5 Composite of geopotential height anomalies at $850-\mathrm{hPa}$ pressure level in the 20 months with highest/ lowest $( \pm)$ teleconnection indices

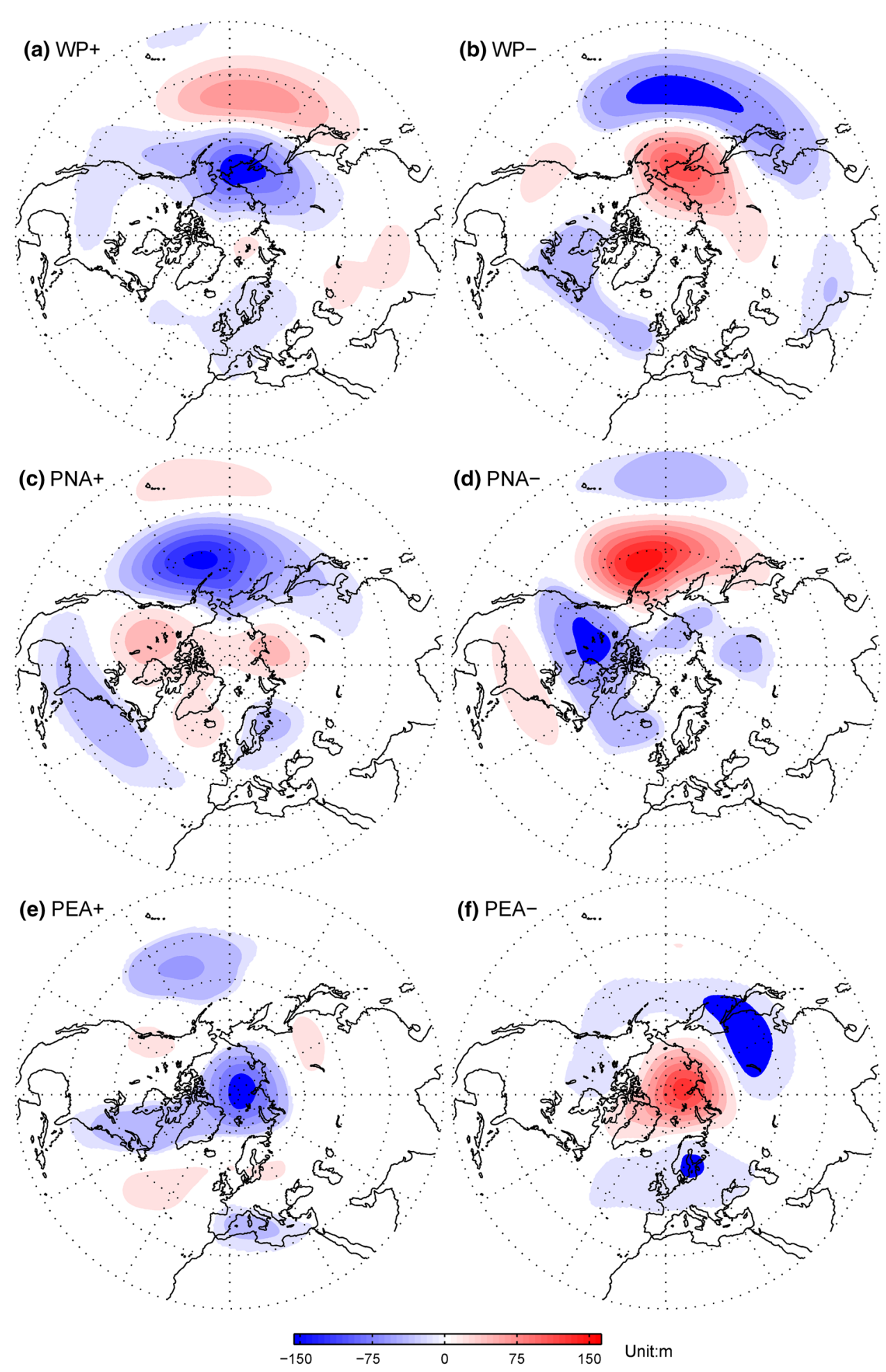

gradient and in turn influencing cyclone activity (Lee et al. 2012). We find that the mean temperature over North Pacific significantly decrease to the north of about $45^{\circ} \mathrm{N}$ over North Pacific in the positive phase of WP, which means the latitudinal gradient of the mean temperature is enhanced in this area (Fig. 6b). This indicates that the enhanced meridional thermal gradient probably accounts for the increase of ETC frequency and intensity over North Pacific in the positive phase of WP. Finally, the difference of Eady growth rate for the two phases of WP is plotted in Fig. 6c indicting the 
Fig. 6 Difference of the zonal wind at $300-\mathrm{hPa}$ pressure level (U300), mean temperature at 850-hPa pressure level and Eady growth rate between the positive and negative phases of WP pattern. Solid lines indicate positive values, while dashed lines indicate negative values. Shaded areas represent the difference significant at the $5 \%$ significance level
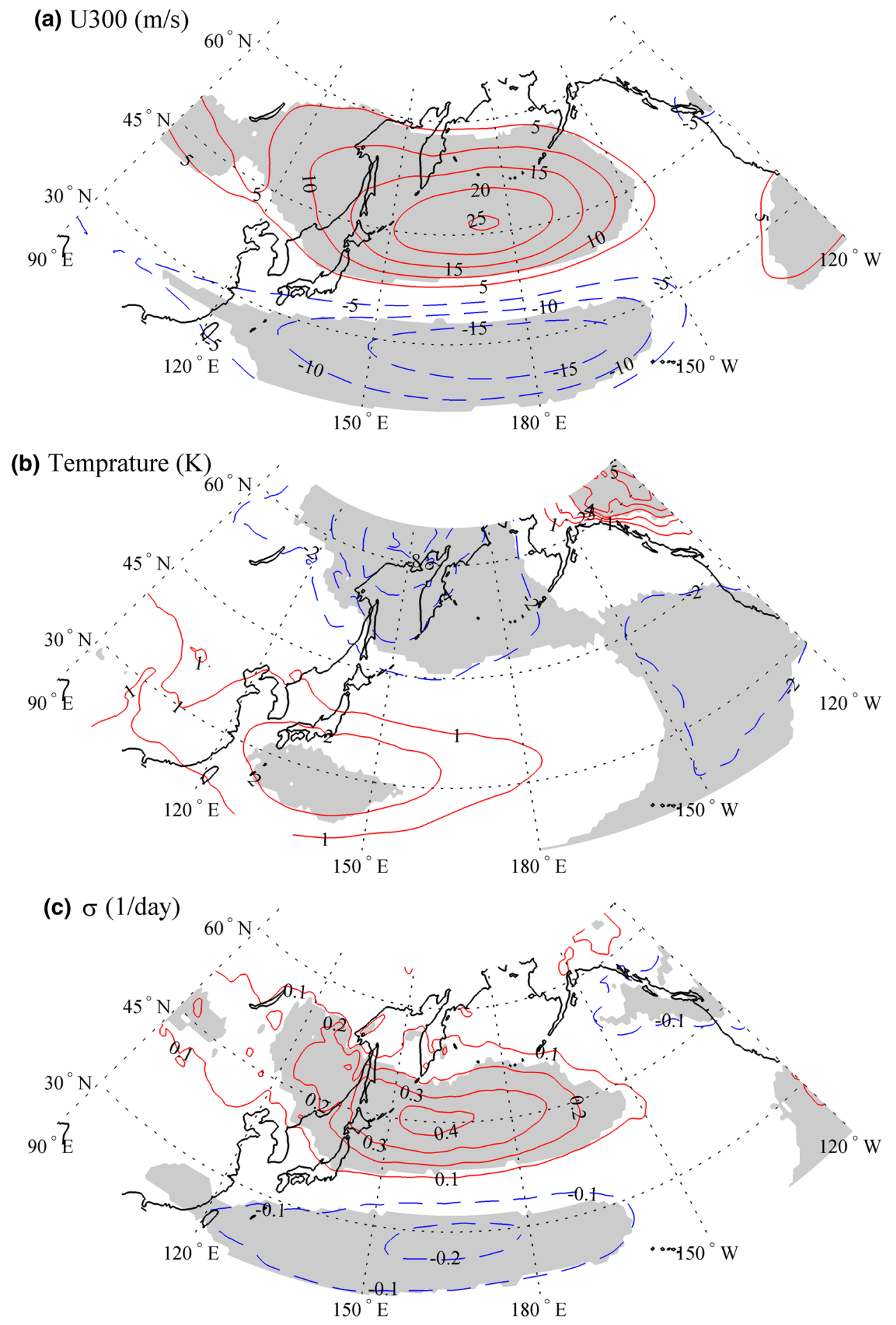

consistence of large-scale baroclinicity and cyclone activity. This consistence again confirms the association of WP and ETC activity over East Asia and Northwest Pacific.

The PNA teleconnection pattern is one of the leading patterns of Northern Hemisphere mid-latitude variability (Barnston and Livezey 1987; Franzke et al. 2011). Its positive phase features above-average geopotential heights near
Hawaii and over the intermountain region of North America, and below-average heights located south of the Aleutian Islands and over the southeastern United States and the Gulf of Mexico (Fig. 5c, d). Previous studies showed that the PNA pattern was largely responsible for the north-south displacement of cyclone tracks in the eastern Pacific (Gulev et al. 2001; Mailier et al. 2006; Seierstad et al. 2007). Figure 7 
Fig. 7 Same as Fig. 6, but for the PNA pattern
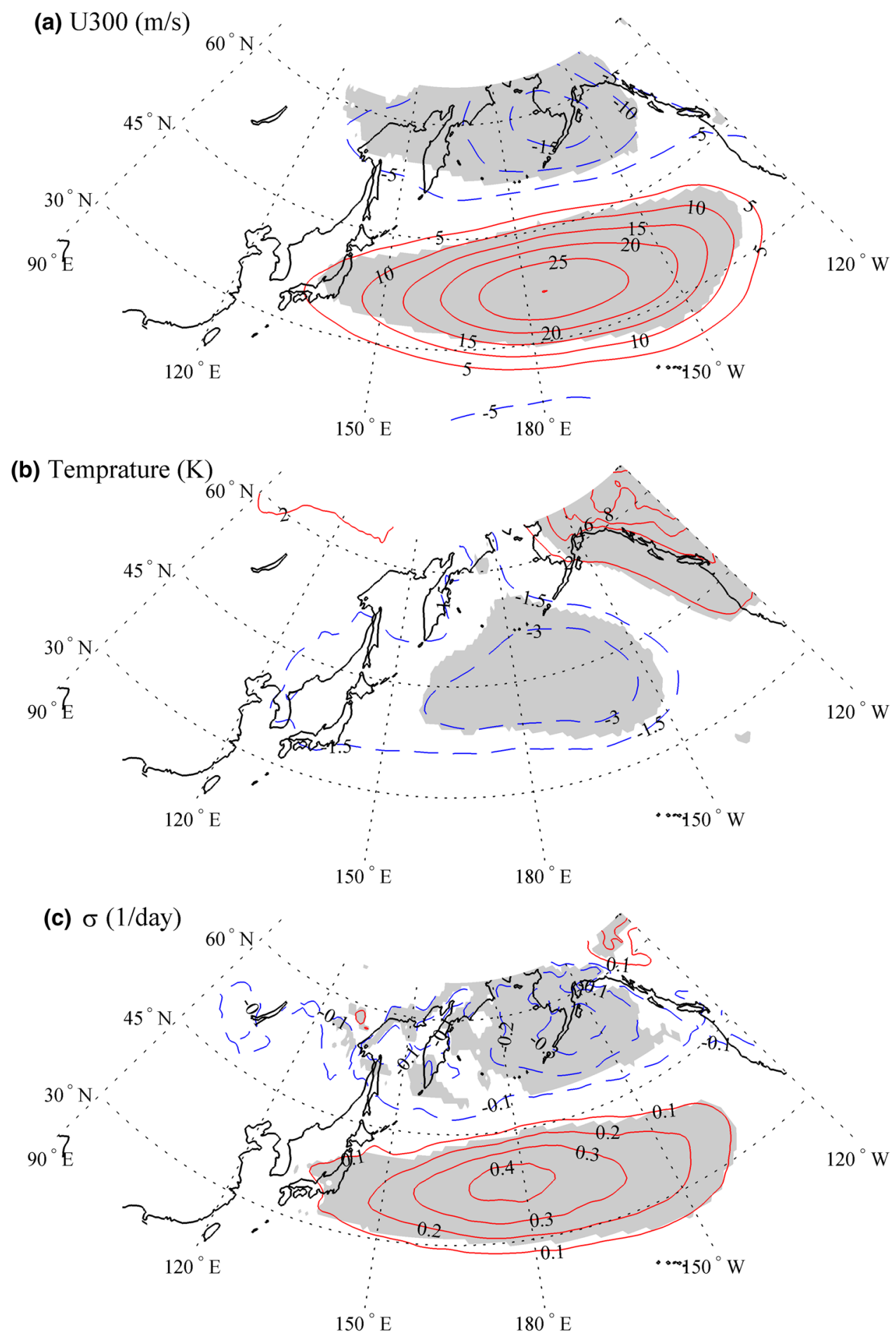

shows the differences of U300, mean temperature at $850-\mathrm{hPa}$ pressure level, and the mid-tropospheric Eady growth rate in the two phases of PNA. The enhanced jet stream, thermal gradient, and mid-tropospheric baroclinicity are responsible for the increase of ETC activity in the positive phase of PNA in the central North Pacific.
The PEA teleconnection pattern is associated with fluctuations in the strength of the circumpolar circulation (Barnston and Livezey 1987). Its positive phase consists of negative geopotential height anomalies over the polar region but positive geopotential height anomaly over northeast Asia (Fig. 5e). This positive geopotential height anomaly is associated with positive temperature anomaly, 
Fig. 8 Same as Fig. 6, but for the PEA pattern

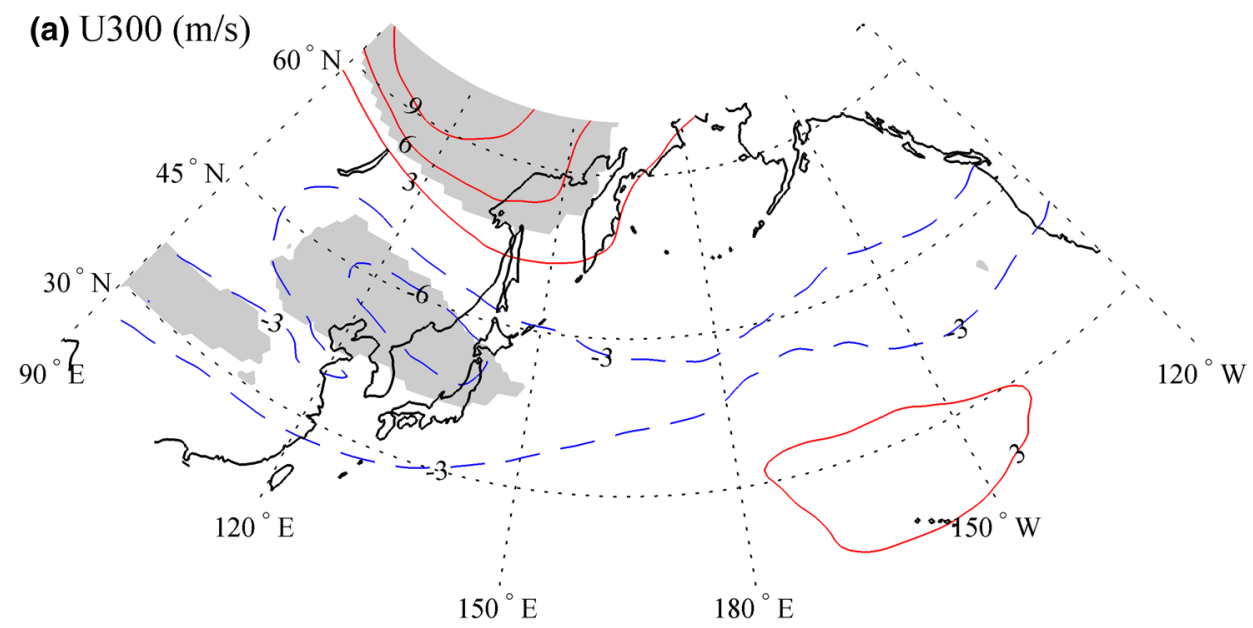

(b) Temprature (K)
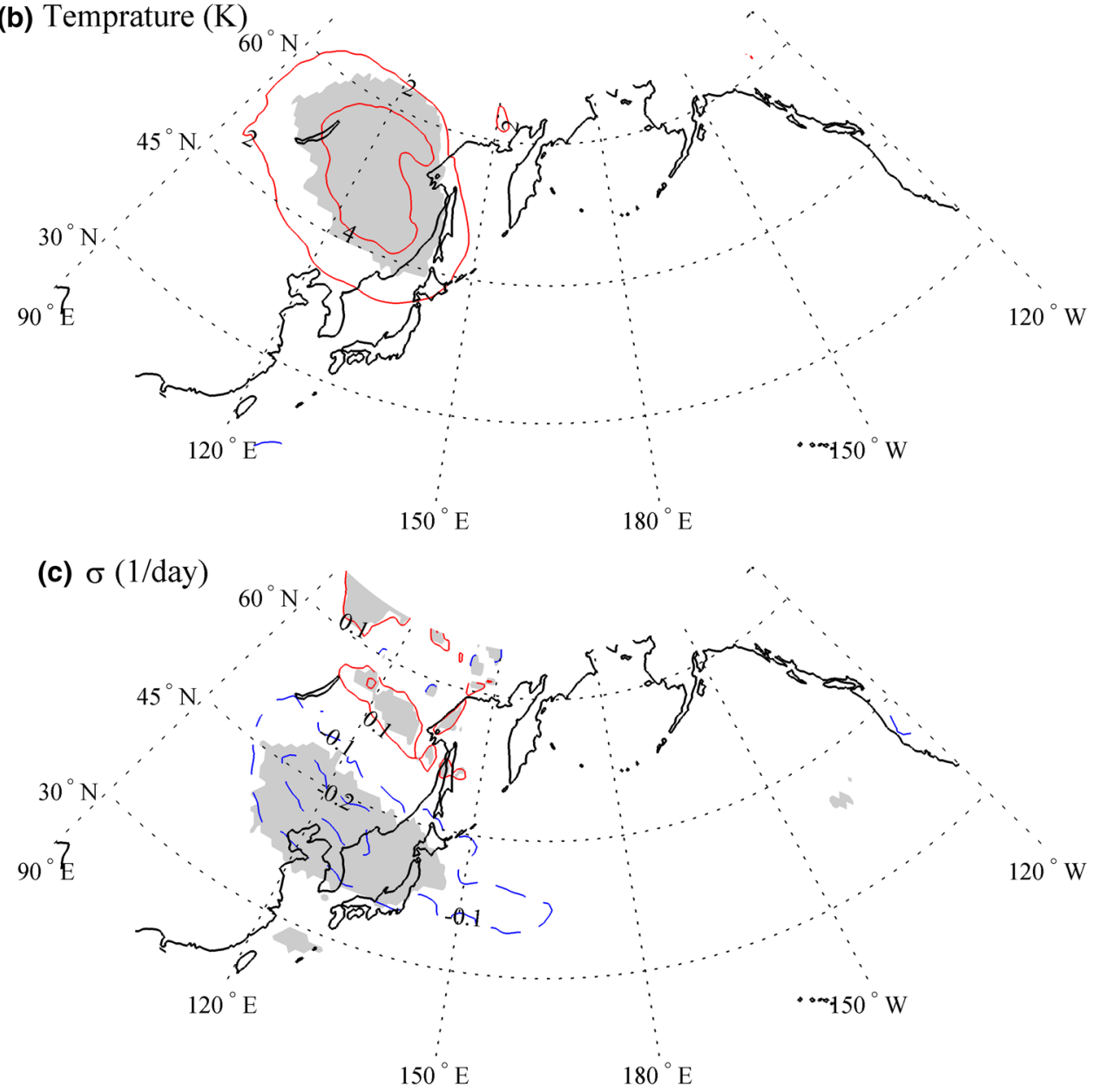

enhanced jet stream and baroclinicity (Fig. 8). However, no significant difference of ETC activity has been detected in this region (Figs. 1, 2, 3, 4). It is concluded that PEA has negligible influence on ETC activity over East Asia and Northwest Pacific.

In this study, we only focus on our attention on the influence of three atmospheric teleconnection patterns on ETC activities. These three teleconnection indices are mutually uncorrelated and suitable for regression analysis. Eichler and Higgins (2006) and Orlanski (2005) have reported the influences of ENSO on the variations of the North Pacific storm tracks. However, the ENSO teleconnection pattern was not included in the regression model to avoid the problem of collinearity in the two regression 
models. An independent investigation on the influence of ENSO or PDO will be presented in future.

\section{Summary}

In this study, the ETC tracks over East Asia and Northwest Pacific were firstly extracted from the ERA-Interim reanalysis data for 40 consecutive extended winters (from November to March) in 1979-2018. The identification and tracking algorithm are based on the maxima of 850-hPa pressure level RV that allow better cyclone detection (Mailier et al. 2006; Flaounas et al. 2014). The ETC tracks are counted and visualized using a hexagonal tessellation rather than the commonly used regular longitude-latitude grids (Elsner et al. 2012a).

Based on the hexagonal tessellation, the associations of wintertime ETCs with three atmospheric teleconnection patterns are firstly investigated using two GLMs, Poisson regression and Gamma regression. GLMs are flexible to handle the serial clustering of ETC counts and non-Gaussian distribution of ETC intensity. Both the regression analysis and composite analysis indicated that ETC counts and intensities were prone to related to WP and PNA, while the influence of PEA on ETC activities was weaker. The meridional variability of ETC activities in positive and negative phases could be partly explained from the view of jet stream, thermal gradient and mid-tropospheric baroclinicity.

Acknowledgements This study was funded by the Key Deployment Project of Center for Ocean Mega-Science, CAS (No. COMS2019J02), the Key Research Program of Frontier Science of Chinese Academy of Sciences (No. ZDBS-LY-7010), the National Natural Science Foundation of China (No. 31570423), and the Key Program of Shandong Natural Science Foundation (No. ZR2020KF031). MG was also partly supported by the Youth Innovation Promotion Association of CAS (2016195). The helpful comments from the editor and all anonymous reviewers are also acknowledged.

Funding This study was funded by the Key Deployment Project of Center for Ocean Mega-Science, CAS (No. COMS2019J02), the Key Research Program of Frontier Science of Chinese Academy of Sciences (No. ZDBS-LY-7010), the National Natural Science Foundation of China (No. 31570423), and the Key Program of Shandong Natural Science Foundation (No. ZR2020KF031). MG was also partly supported by the Youth Innovation Promotion Association of CAS (2016195).

Availability of data and material The reanalysis data was provided by ECMWF. The teleconnection indices were provided by provided by NOAA Center for Weather and Climate Prediction.

Code availability The computer code for ETC identification and tracking was accessed from Dr. Flaounas via personal communication.

\section{Declarations}

Conflict of interest The authors declare no conflicts of interest.

\section{References}

Adachi S, Kimura F (2007) A 36-year climatology of surface cyclogenesis in East Asia using high-resolution reanalysis data. SOLA 3:113-116

Barnston AG, Livezey RE (1987) Classification, seasonality, and persistence of low-frequency atmospheric circulation patterns. Mon Weather Rev 115:1083-1126

Barton NP, Ellis AW (2009) Variability in wintertime position and strength of the North Pacific jet stream as represented by re-analysis data. Int J Climatol 29:851-862

Blender R, Raible CC, Lunkeit F (2015) Non-exponential return time distributions for vorticity extremes explained by fractional Poisson processes. Q J R Meteorol Soc 141:249-257

Blender R, Raible CC, Franzke CLE (2017) Vorticity and geopotential height extreme values in ERA-Interim data during boreal winters. Q J R Meteorol Soc 143:634-640

Catto JL (2016) Extratropical cyclone classification and its use in climate studies. Rev Geophys 54:486-520

Chang EKM, Fu Y (2002) Interdecadal variations in northern hemisphere winter storm track intensity. J Clim 15:642-658

Chang EKM, Yau AMW (2016) Northern Hemisphere winter storm track trends since 1959 derived from multiple reanalysis datasets. Clim Dyn 47:1435-1454

Chang EKM, Lee S, Swanson KL (2002) Storm track dynamics. J Clim 15:2163-2183

Chen S-J, Kuo Y-H, Zhang P-Z, Bai Q-F (1991) Synoptic climatology of cyclogenesis over East Asia, 1958-1987. Mon Weather Rev 119:1407-1418

Chen L, Tan B, Kvamstø NG, Johannessen OM (2014) Wintertime cyclone/anticyclone activity over China and its relation to upper tropospheric jets. Tellus 66A:21889

Choi K-S, Moon IJ (2012) Influence of the Western Pacific teleconnection pattern on Western North Pacific tropical cyclone activity. Dyn Atmos Oceans 57:1-16

Chung Y-S, Hage KD, Reinelt ER (1976) On lee cyclogenesis and airflow in the Canadian Rocky Mountains and the East Asian Mountains. Mon Weather Rev 104:879-891

Dee DP, Uppala SM, Simmons AJ, Berrisford P, Poli P, Kobayashi S, Andrae U, Balmaseda MA, Balsamo G, Bauer P, Bechtold PM, Beljaars AC, van de Berg L, Bidlot J, Bormann N, Delsol C, Dragani R, Fuentes M, Geer AJ, Haimberger L, Healy SB, Hersbach H, Hólm EV, Isaksen L, Kållberg P, Köhler M, Matricardi M, McNally AP, Mong-Sanz BM, Morcrette JJ, Park BK, Peubey C, de Rosnay P, Tavolato C, Thépaut JN, Vitart F (2011) The ERA-Interim reanalysis: configuration and performance of the data assimilation system. Q J R Meteorol Soc 137:553-597

Dobson AJ (1990) An introduction to generalized linear models. Chapman and Hall, London

Economou T, Stephenson DB, Pinto JG, Shaffrey LC, Zappa G (2015) Serial clustering of extratropical cyclones in a multi-model ensemble of historical and future simulations. Q J R Meteorol Soc 141:3076-3087

Eichler T, Higgins W (2006) Climatology and ENSO-related variability of North American extratropical cyclone activity. J Clim 19:2076-2093

Elsner JB, Villarini G (2011) Statistical models for tropical cyclone activity (unpublished manuscript)

Elsner JB, Hodges RE, Jagger TH (2012a) Spatial grids for hurricane climate research. Clim Dyn 39(1-2):21-36

Elsner JB, Trepanier JC, Strazzo SE, Jagger TH (2012b) Sensitivity of limiting hurricane intensity to ocean warmth. Geophys Res Lett 39:L11702

Flaounas E, Kotroni V, Lagouvardos K, Flaounas I (2014) CycloTRACK (v1.0)-tracking winter extratropical cyclones 
based on relative vorticity: sensitivity to data filtering and other relevant parameters. Geosci Model Dev 7:1841-1853

Franzke CLE (2013) Persistent regimes and extreme events of the North Atlantic atmospheric circulation. Philos Tans R Soc A 371:20110471

Franzke C, Feldstein SB, Lee S (2011) Synoptic analysis of the PacificNorth American teleconnection pattern. Q J R Meteorol Soc 137:329-346

Franzke CLE, Barbosa S, Blender R, Fredriksen HB, Laepple T, Lambert F, Nilsen T, Rypdal K, Rypdal M, Scotto MG, Vannitsem S, Watkins NW, Yang L, Yuan N (2020) The structure of climate variability across scales. Rev Geophys 58:e2019RG000657

Fraza E, Elsner JB (2014) A spatial climatology of North Atlantic hurricane intensity change. Int J Climatol 34:2918-2924

Gulev SK, Zolina O, Grigoriev S (2001) Extratropical cyclone variability in the northern hemisphere winter from NCEP/NCAR reanalysis data. Clim Dyn 17:795-809

Hawcroft MK, Shaffrey LC, Hodges KI, Dacre HF (2012) How much Northern Hemisphere precipitation is associated with extratropical cyclones? Geophs Res Lett 39:L24809

Hoskins BJ, Hodges KI (2002) New perspectives on the Northern Hemisphere winter storm tracks. J Atmos Sci 59:1041-1061

Hoskins BJ, Valdes PJ (1990) On the existence of storm-tracks. J Atmos Sci 47:1854-1864

Hunter A, Stephenson DB, Economou T, Holland M, Cook I (2016) New perspectives on the collective risk of extratropical cyclones. Q J R Meteorol Soc 142:243-256

Iwao K, Inatsu M, Kimoto M (2012) Recent changes in explosively developing extratropical cyclones over the Winter Northwestern Pacific. J Clim 25:7282-7296

Katz RW (2002) Stochastic modeling of hurricane damage. J Appl Meteorol 41(7):754-762

Kozar ME, Mann ME, Camargo SJ, Kossin JP, Evans JL (2012) Stratified statistical models of North Atlantic basin-wide and regional tropical cyclone counts. J Geophys Res-Atmos 117:D18103

Lee S, Lee J, Wang B, Ha K, Heo K, Jin F, Straus DM, Shukla J (2012) Interdecadal changes in the storm track activity over the North Pacific and North Atlantic. Clim Dyn 39:313-327

Lee J, Son S-W, Cho H-O, Kim J, Cha D-H, Gyakum JR, Chen D (2020) Extratropical cyclones over East Asia: climatology, seasonal cycle, and long-term trend. Clim Dyn 54:1131-1144

Mailier PJ, Stephenson DB, Ferro CAT, Hodges KI (2006) Serial clustering of extratropical cyclones. Mon Weather Rev 134(8):2224-2240

Orlanski I (2005) A new look at the Pacific storm track variability: sensitivity to tropical SSTs and upstream seeding. J Atmos Sci 62:1367-1390

Pinto JG, Zacharias S, Fink AH, Leckebusch GC, Ulbrich U (2009) Factors contributing to the development of extreme North Atlantic cyclones and their relationship with the NAO. Clim Dyn 32:711-737

Pinto JG, Reyers M, Ulbrich U (2011) The variable link between PNA and NAO in observations and in multi-century CGCM simulations. Clim Dyn 36:337-354

Pinto JG, Bellenbaum N, Karremann MK, Della-Marta PM (2013) Serial clustering of extratropical cyclones over the North Atlantic and Europe under recent and future climate conditions. J Geophys Res-Atmos 118(22):12476-12485

Pinto JG, Gómara I, Masato G, Dacre HF, Woollings T, Caballero R (2014) Large-scale dynamics associated with clustering of extratropical cyclones affecting Western Europe. J Geophys Res-Atmos 119(24):13704-13719
Plante M, Son SW, Atallah E, Gyakum J, Grise K (2015) Extratropical cyclone climatology across eastern Canada. Int J Climatol 35:2759-2776

Raible CC (2007) On the relation between extremes of midlatitude cyclones and the atmospheric circulation using ERA40. Geophs Res Lett 34(7):L07703

Reboita MS, da Rocha RP, Ambrizzi T, Gouveia CD (2015) Trend and teleconnection patterns in the climatology of extratropical cyclones over the Southern Hemisphere. Clim Dyn 45:1929-1944

Seierstad IA, Strphenson DB, Kvamstø NG (2007) How useful are teleconnection patterns for explaining variability in extratropical storminess? Tellus 59A:170-181

Tamarin-Brodsky T, Kaspi Y (2017) Enhanced poleward propagation of storms under climate change. Nat Geosci 10(12):908-913

Trepanier JC, Ellis KN, Tucker CS (2015) Hurricane risk variability along the Gulf of Mexico Coastline. PLOS ONE 10(3):e0118196

Ulbrich U, Leckebusch GC, Pinto JG (2009) Extra-tropical cyclones in the present and future climate: a review. Theor Appl Climatol 96:117-131

Varino F, Arbogast P, Joly B, Riviere G, Fandeur ML, Bovy H, Granier JB (2019) Northern Hemisphere extratropical winter cyclones variability over the 20th century derived from ERA-20C reanalysis. Clim Dyn 52:1027-1048

Vitolo R, Stephenson DB, Cook IM, Mitchell-Wallace K (2009) Serial clustering of intense European storms. Meteorol Z 18(4):411-424

Wang XLL, Swail VR, Zwiers FW (2006) Observed changes in cyclone activity in Canada and their relationships to major circulation regimes. J Clim 19:895-906

Wang X, Zhai P, Wang C (2009) Variations in extratropical cyclone activity in northern East Asia. Adv Atmos Sci 26(3):471-479

Whittaker LM, Horn LH (1984) Northern Hemisphere extratropical cyclone activity for four mid-season months. Int J Climatol 4:297-310

Xie N, Gao M, Gao Z (2019) Climatology of Winter Extratropical Cyclones over the Coastal Waters of China. J Atmos Sci Res 2:37-45

Yonekura E, Hall TM (2011) A statistical model of tropical cyclone tracks in the Western North Pacific with ENSOdependent cyclogenesis. J Appl Meteorol Climatol 50:1725-1739

Yoshida A, Asuma Y (2004) Structures and environment of explosively developing extratropical cyclones in the Northwestern Pacific region. Mon Weather Rev 132:1121-1142

Zhang YC, Rossow WB (1997) Estimating meridional energy transports by the atmospheric and oceanic general circulations using boundary fluxes. J Clim 10:2358-2373

Zhang YX, Ding YH, Li QP (2012) A climatology of extratropical cyclones over East Asia during 1958-2001. Acta Oceanol Sin 26(3):261-277

Zhu Q, Lin J, Shou S, Tang D (2000) Principles of synoptic meteorology. China Meteorological Press, Beijing (in Chinese)

Zhu XJ, Sun JLK, Liu ZY, Liu QY, Martin HE (2007) A synoptic analysis of the interannual variability of winter cyclone activity in the Aleutian low region. J Clim 20:1523-1538

Publisher's Note Springer Nature remains neutral with regard to jurisdictional claims in published maps and institutional affiliations. 